\title{
Axial Compressive Behavior of Steel Fiber-Reinforced Recycled Coarse Aggregate Concrete-Filled Short Circular Steel Columns
}

\author{
Qiao-Huan Wang, ${ }^{1,2}$ Jiong-Feng Liang, ${ }^{3}$ Chun-Feng $\mathrm{He}^{3}$ and Wei Li ${ }^{4}{ }^{4}$ \\ ${ }^{1}$ School of Water Resources and Environmental Engineering, East China University of Technology, Nanchang, China \\ ${ }^{2}$ School of Water and Environment, Chang'an University, Xi'an, China \\ ${ }^{3}$ Faculty of Civil\&Architecture Engineering, East China University of Technology, Nanchang, China \\ ${ }^{4}$ College of Civil Engineering and Architecture, Wenzhou University, Wenzhou, Zhejiang, China \\ Correspondence should be addressed to Wei Li; liw1981@126.com
}

Received 28 February 2021; Revised 17 March 2021; Accepted 24 March 2021; Published 5 April 2021

Academic Editor: Shengwen Tang

Copyright $\odot 2021$ Qiao-Huan Wang et al. This is an open access article distributed under the Creative Commons Attribution License, which permits unrestricted use, distribution, and reproduction in any medium, provided the original work is properly cited.

\begin{abstract}
This paper attempts to explore the effects of recycled coarse aggregate content, steel fiber content, and concrete strength on the axial compressive behavior of steel fiber-reinforced recycled coarse aggregate (RCA) concrete-filled circular steel stub columns. A total of 14 short columns are tested. The results show that using RCA in concrete will reduce the bearing capacity of short columns, but the increase in steel fiber content and concrete strength can eliminate this shortcoming. Not only that, the concrete strength has a great influence on the ductility and stiffness of the specimen.
\end{abstract}

\section{Introduction}

Nowadays, the speed of world economic development is accelerating, and the scale of infrastructure construction is getting bigger and bigger. Every year, the construction of new buildings consumes several billion tons of natural coarse aggregate. At the same time, the demolition of a large number of old buildings generates a lot of construction waste. And, the urban construction waste generated by the construction or demolition of buildings in China each year reaches about 2 billion tons, accounting for about $40 \%$ of the total urban waste, but the utilization rate of construction waste is not high, most of the construction waste is buried and accumulated, occupying a lot of land and space and causing secondary disasters to the environment. Therefore, the recycling of construction waste has significant economic and environmental benefits [1-7]. According to the literature view [8-12], it was found that RCA concrete has lower strength, lower elastic modulus, larger shrinkage, and larger creep than the conventional concrete.

At present, recycled aggregate concrete is mainly used in the low stressed structure. To overcome the defects of recycled aggregate concrete, recycled aggregate concretefilled steel tube is a feasible way. The strength and ductility of the recycled aggregate concrete core can be enhanced by the confinement of steel tube. Some scholars have carried out research on recycled aggregate concrete-filled steel tube columns. For example, Xu et al. [13] proposed some data mining analyses to evaluate the performance of recycled aggregate concrete-filled steel tube under the axial and lateral load. Chen et al. [14] explored the seismic performance of recycled concrete-filled steel tube columns. It was found that the hysteretic curve of recycled concrete-filled steel tube column is similar to that of ordinary concretefilled steel tube column.

Steel fiber (SF) is a new type of concrete mixing material. Steel fiber will not pellet in the concrete and is evenly distributed. Its addition, as adding other types of fibers such as PVA and polymeric fibers the same, can improve the bonding properties of concrete and can also increase the strength and toughness of concrete [15, 16]. Although volume fraction of SF can significantly affect the workability of concrete, it has been increasingly used in structures because it significantly improves the mechanical properties of 
TABle 1: Details of all specimens.

\begin{tabular}{|c|c|c|c|c|c|c|c|c|c|c|}
\hline $\begin{array}{l}\text { Specimen } \\
\text { no. }\end{array}$ & $\begin{array}{c}\text { RCA } \\
(\%)\end{array}$ & $\begin{array}{l}\text { SF } \\
(\%)\end{array}$ & $\begin{array}{c}\mathrm{RCA} \\
\left(\mathrm{kg} \cdot \mathrm{m}^{-3}\right)\end{array}$ & $\begin{array}{c}\mathrm{SF} \\
\left(\mathrm{kg} \cdot \mathrm{m}^{-3}\right)\end{array}$ & $\begin{array}{c}\mathrm{NCA} \\
\left(\mathrm{kg} \cdot \mathrm{m}^{-3}\right)\end{array}$ & $\begin{array}{c}\text { Sand } \\
\left(\mathrm{kg} \cdot \mathrm{m}^{-3}\right)\end{array}$ & $\begin{array}{c}\text { Cement } \\
\left(\mathrm{kg} \cdot \mathrm{m}^{-3}\right)\end{array}$ & $\begin{array}{c}\text { Water } \\
\left(\mathrm{kg} \cdot \mathrm{m}^{-3}\right)\end{array}$ & $\begin{array}{c}\text { Concrete } \\
\text { strength grade }\end{array}$ & $f_{c u}(\mathrm{MPa})$ \\
\hline TS-1 & 0 & 0.9 & 0 & 70.7 & 1257 & 531 & 422 & 190 & C30 & 42.9 \\
\hline TS-2 & 50 & 0.9 & 628.5 & 70.7 & 628.5 & 531 & 422 & 190 & C30 & 32.6 \\
\hline TS-3 & 100 & 0.9 & 1257 & 70.7 & 0 & 531 & 422 & 190 & C30 & 29.8 \\
\hline TS-4 & 50 & 0.6 & 628.5 & 47.1 & 628.5 & 531 & 422 & 190 & C30 & 28.6 \\
\hline TS-5 & 50 & 1.2 & 628.5 & 94.2 & 628.5 & 531 & 422 & 190 & C30 & 35.5 \\
\hline TS-6 & 100 & 0.6 & 1257 & 47.1 & 0 & 531 & 422 & 190 & C30 & 26.6 \\
\hline TS-7 & 100 & 1.2 & 1257 & 94.2 & 0 & 531 & 422 & 190 & C30 & 34.2 \\
\hline TS- 8 & 50 & 0.9 & 621 & 70.7 & 621 & 640 & 328 & 190 & $\mathrm{C} 20$ & 24.9 \\
\hline TS-9 & 50 & 0.9 & 642.5 & 70.7 & 642.5 & 475 & 500 & 190 & C40 & 37.1 \\
\hline TS-10 & 100 & 0.9 & 1242 & 70.7 & 0 & 640 & 328 & 190 & C20 & 22.6 \\
\hline TS-11 & 100 & 0.9 & 1285 & 70.7 & 0 & 475 & 500 & 190 & C40 & 34.7 \\
\hline TS-12 & 0 & 0 & 0 & 0 & 1257 & 531 & 422 & 190 & C30 & 29.5 \\
\hline TS-13 & 50 & 0 & 628.5 & 0 & 628.5 & 531 & 422 & 190 & C30 & 27.1 \\
\hline TS-14 & 100 & 0 & 1257 & 0 & 0 & 531 & 422 & 190 & C30 & 25.8 \\
\hline
\end{tabular}

concrete. So, adding SF in RCA concrete can make up its insufficient performance. Carneiro et al. [17] analyzed the compressive stress-strain behavior of steel fiber-reinforced recycled aggregate concrete (RAC). Mohseni et al. [18] found that the behavior of RCA concrete was improved by adding steel or polypropylene fibers. Gao et al. [19] revealed that adding SF in RAC enhanced its compressive and flexural behavior.

The addition of steel fibers can alleviate the friability and fissility of RAC. So, using SF-reinforced RCA concrete as infilling in steel tube is an effective method to improve its performance [20]. However, there are few research studies on this composite structure. Herein, the axial compressive behavior of steel fiber-reinforced RCA concrete-filled circular steel tube is investigated to expand the application of RCA concrete.

\section{Experimental Programme}

2.1. Specimen Design. In order to study the influence of the following parameters: steel fiber (SF) content, recycled coarse aggregate (RCA) content, and concrete strength on axial compressive behavior of steel fiber-reinforced recycled aggregate concrete-filled circular steel stub columns, 14 specimens are tested. All specimens have an external diameter of $114 \mathrm{~mm}$, a thickness of $3 \mathrm{~mm}$, and a length of $500 \mathrm{~mm}$. Four SF content in a volume fraction of $0,0.6 \%, 0.9 \%$, and $1.2 \%$ are used in this test. Three different RCA contents with quality replacement rate of RCA for natural aggregate of $0,50 \%$, and $100 \%$ and three concrete strength grades of C20 (20 MPa), C30 (30 MPa), and $\mathrm{C} 40(40 \mathrm{MPa})$ are considered. Table 1 lists the details of tested specimens.

2.2. Material Properties. The steel tube used in the test is a welded circular steel tube. And, the average values of yield strength, ultimate tensile strength, and elastic modulus for the steel tubes are $269 \mathrm{MPa}, 363 \mathrm{MPa}$, and $210 \mathrm{GPa}$, respectively.

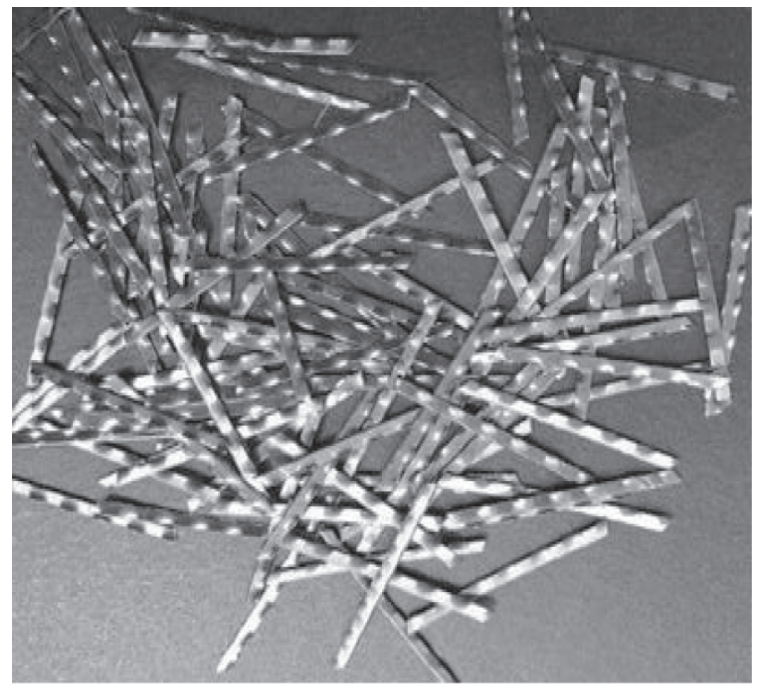

FIgURE 1: Steel fiber.

Ordinary Portland cement with a 28-day compressive strength of $42.5 \mathrm{MPa}$ is used in this investigation. The coarse aggregate are natural coarse aggregates (NCA) and recycled coarse aggregates (RCA), which are in the particle size range $5-20 \mathrm{~mm}$. The used fine aggregates are river sand. The shear steel fiber, with a tensile strength of $600 \mathrm{MPa}$, a length of $35 \mathrm{~mm}$, and a diameter of $0.6 \mathrm{~mm}$, is used. The shear-shaped steel fiber is shown in Figure 1. The mix proportions of the new concrete are summarized in Table 1, which are without the effects of admixtures such as fly ash and silica fume $[21,22]$. For each concrete mix, three concrete cubes with a dimension of $150 \times 150 \times 150 \mathrm{~mm}$ are prepared to determine the cubic compressive strength $\left(f_{\mathrm{cu}}\right)$, which is shown in Table 1.

2.3. Testing and Calculation Methods. All tested specimens are performed on a $3000 \mathrm{kN}$ pressure testing machine, as shown in Figure 2. Two linear voltage displacement transducers (LVDTs) are used along the specimen height to measure the axial deformation. The load and displacement 


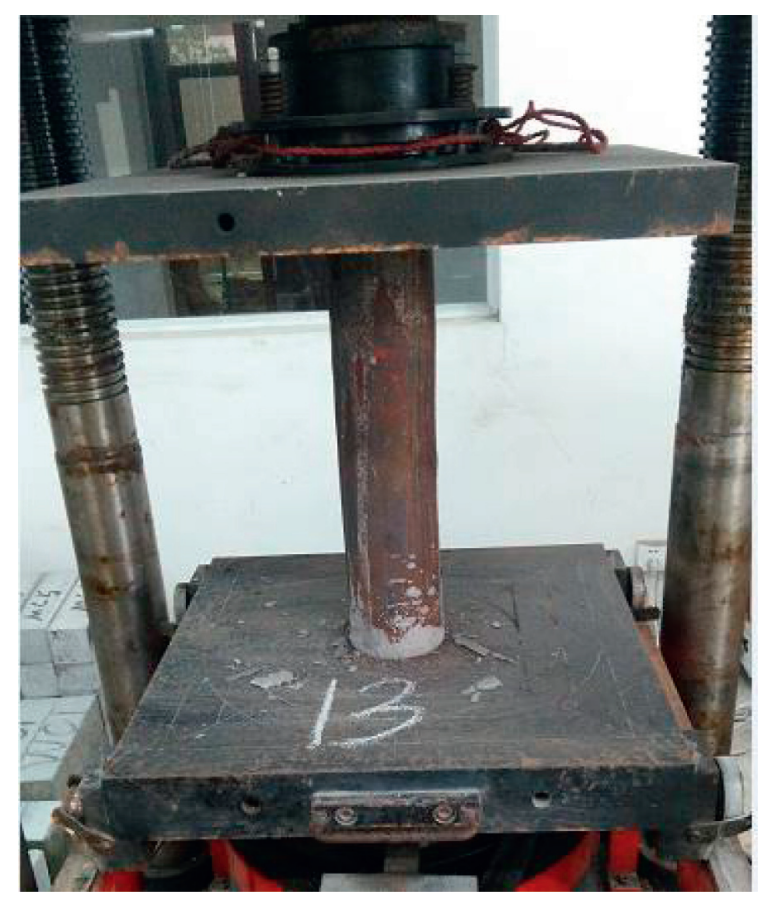

Figure 2: Test setup.

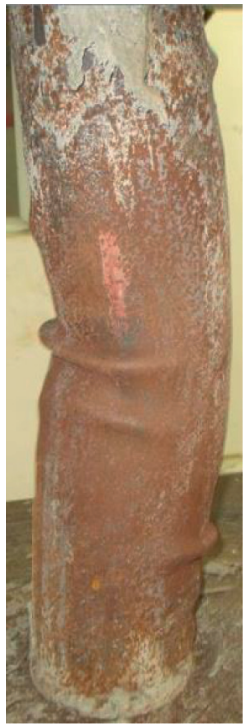

(a)

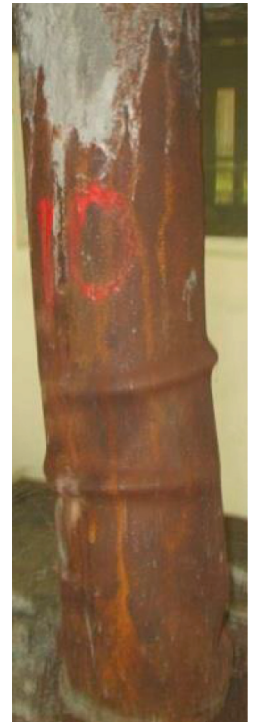

(b)

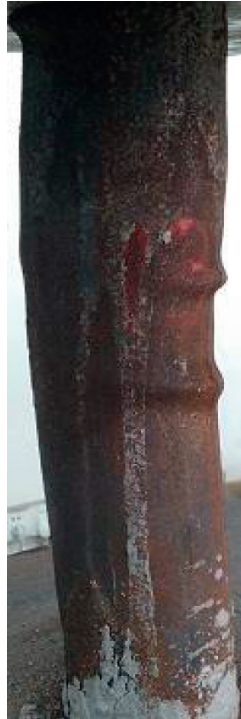

(c)

FIgURE 3: Typical failure modes of tested specimens. (a) TS-1. (b) TS-10. (c) TS-13.

data in the test are collected by the data acquisition instrument.

Different parameters may have various influences on the ductility and deformability of columns. The displacement ductility coefficient $(\mu)$ is herein defined as follows:

$$
\mu=\frac{\Delta_{m}}{\Delta_{y}}
$$

where $\Delta_{m}$ is the ultimate displacement corresponding to the ultimate load and $\Delta_{y}$ is the yield displacement corresponding to yield load.

The secant stiffness $(K)$ is used to describe the stiffness change of the specimen, which is defined as follows:

$$
K=\frac{P_{y}}{\varepsilon_{y}},
$$



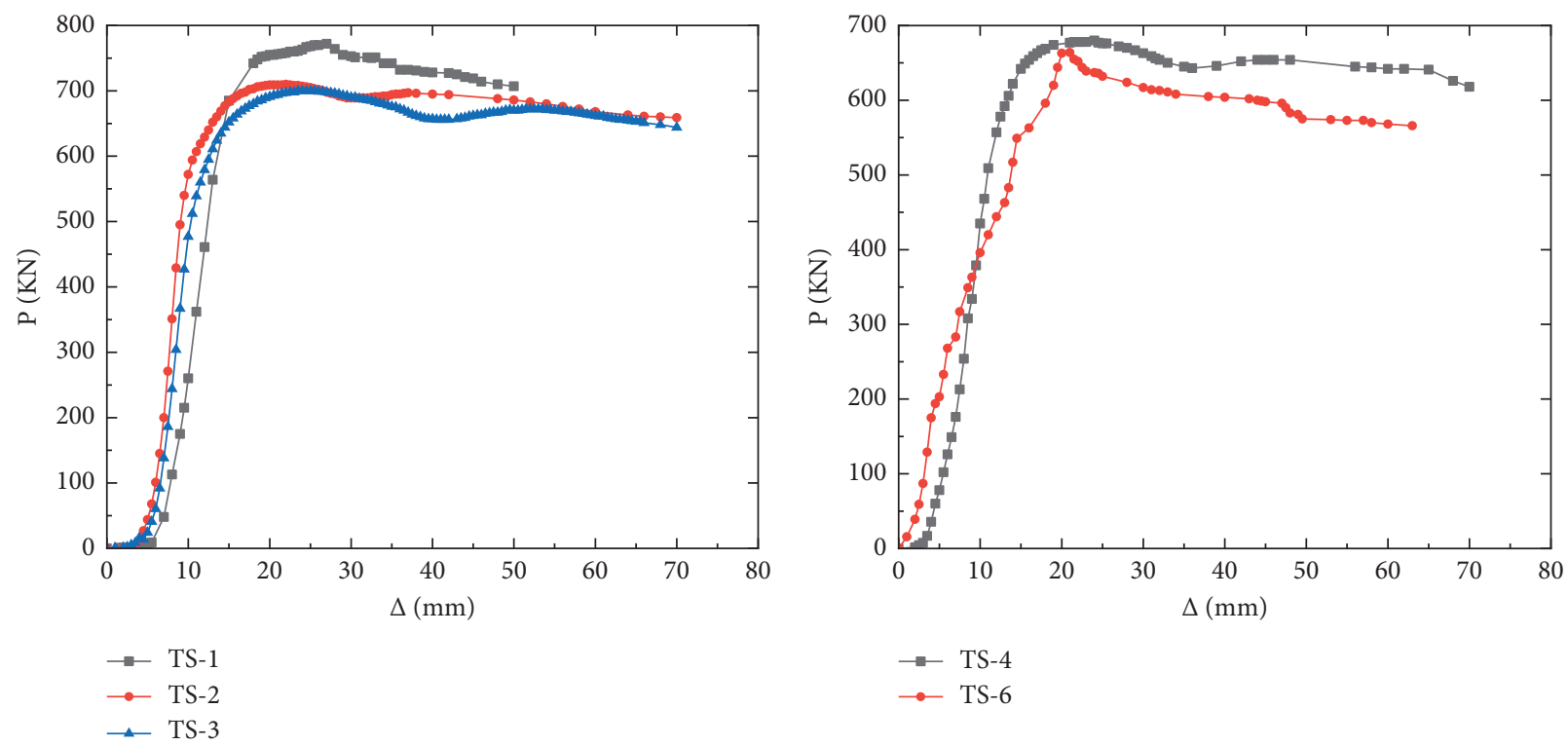

(a)
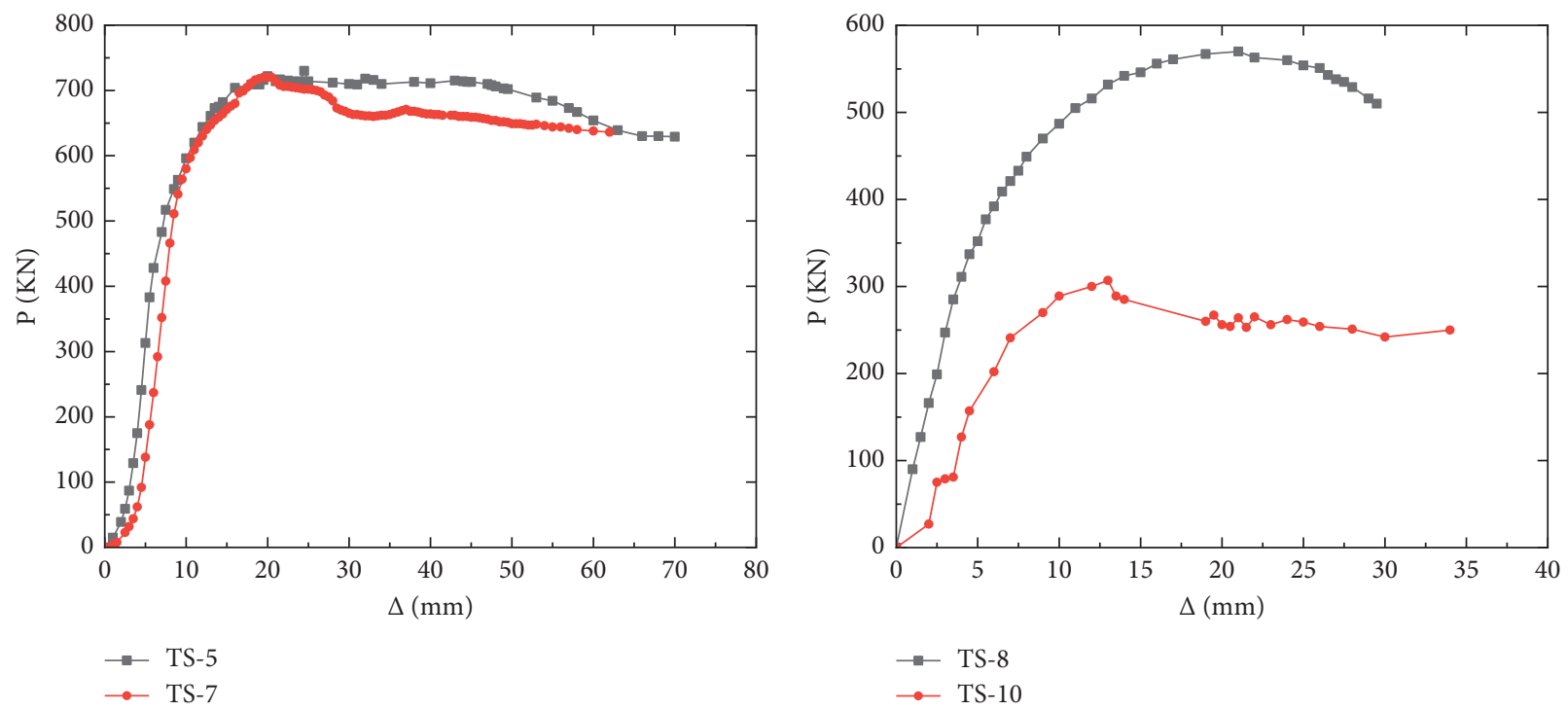

(c)

(d)

FIGURE 4: Continued. 


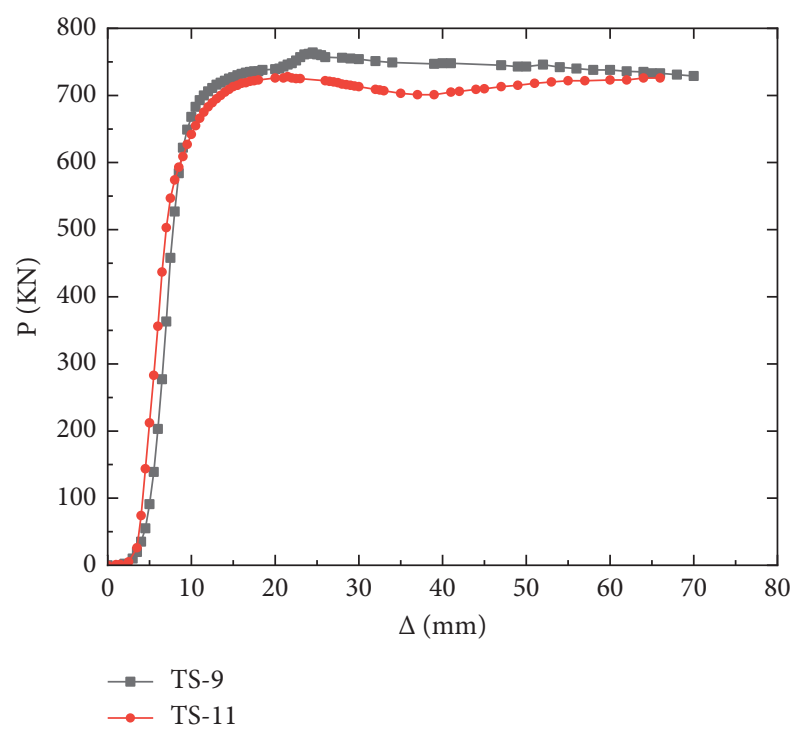

(e)

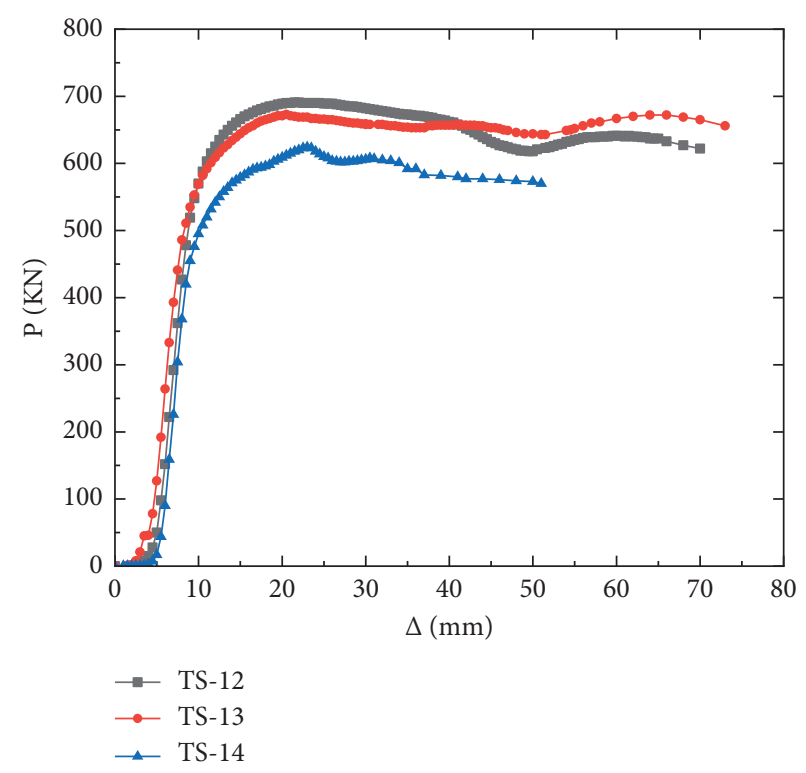

(f)

Figure 4: Load-displacement curve with different RCA contents.

where $P_{y}$ is the yield load and $\varepsilon_{y}$ is the strain corresponding to the yield load.

\section{Results and Discussion}

3.1. Test Phenomenon and Failure Mode. All tested specimens undergo a similar failure process during loading. There is no obvious phenomenon for the specimens at the beginning of the experiment. At this time, the specimen is in the elastic stage, and the stress and strain become linear growth. As the load continues to increase, the test specimens begin to leave the elastic stage and enter the elastic-plastic stage. During this stage, some sound can be heard. The sound is the peeling sound of the bonding interface between concrete and steel tube and the cracking sound of concrete. With the increase of loading, the difference between concrete and steel tube deformation becomes larger due to the different elastic modulus of concrete and steel tube. As the loading continues, the specimens begin to expand slightly. When the load reaches about $95 \%$ of the ultimate load, it can be seen that the steel tube buckles and, basically, it occurs in the middle of the specimen. Comparing the failure modes of different specimens, it is found that the specimens with RCA have more obvious buckling phenomenon and more significant hoop expansion, indicating that Poisson's ratio of recycled aggregate concrete is smaller than that of natural concrete. And, the typical failure modes of the tested specimens are shown in Figure 3.

3.2. Load-Displacement Relationship. It can be seen from Figure 4 that the bearing capacity of the specimen decreases as the RCA content increases. The RCA content has a greater impact on the bearing capacity of the specimen without steel fiber. The greater the SF content, the closer the load- displacement curve of the specimen, which means that the greater the SF content, the less the effect of the RCA content on its performance. When the concrete strength grade is $\mathrm{C} 20$, the change in the RCA content has a huge impact on the bearing capacity of the specimen. As shown in Figure 5, when the RCA content increases from $50 \%$ to $100 \%$, the ultimate bearing capacity decreases by $46 \%$. For the specimens with concrete strength grades of $\mathrm{C} 30$ or $\mathrm{C} 40$, the effect of the RCA content is relatively small.

As shown in Figure 6, the shape of the load-displacement curve of the specimen does not vary hugely with increasing SF content, but the ultimate bearing capacity of the specimen reduces. For the four specimens with a 50\% replacement rate of RCA, the ultimate bearing capacity has the smallest variation range, and the bearing capacity remains between $650 \mathrm{kN}$ and $750 \mathrm{kN}$. The SF content has a greater impact on the bearing capacity of the specimens with $100 \%$ RCA content.

As shown in Figure 7, the ultimate bearing capacity of the specimen increases with the increase of the strength of the concrete. It is worth noting that when the concrete strength grade is $\mathrm{C} 20$, the shape of load-displacement curve has a significant change regardless of whether the RCA content or not. And, the elastic deformation stage is hugely decreased, and it enters the plastic stage faster than the specimens with concrete strength grade of $\mathrm{C} 30$ or C40. The ultimate bearing capacity of the specimen with concrete strength grade of C20 reduces $20 \%$ and 56\% than that of the specimen with concrete strength grade of C30 or C40.

3.3. Ductility. The calculated ductility coefficients are plotted in Figure 8. It can be seen that the displacement ductility coefficient of the specimens ranges from 1.8 to 2.6. Besides, more than $70 \%$ of the specimens have ductility coefficients in 


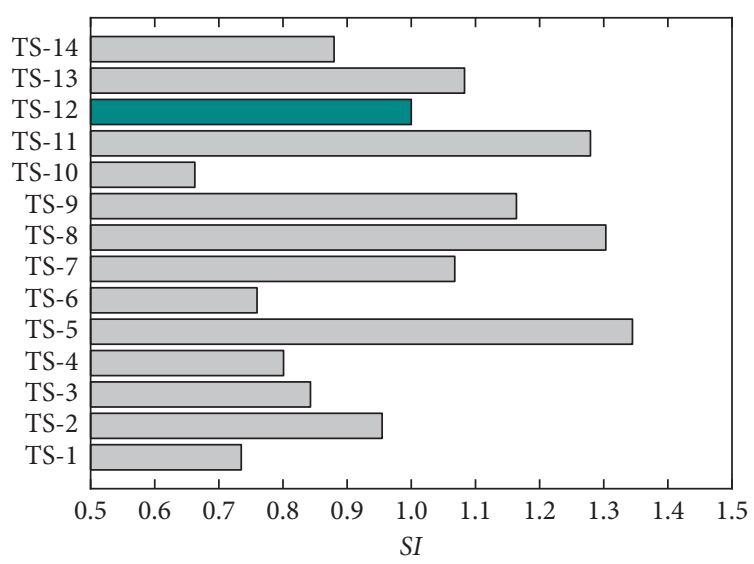

Figure 5: SI.
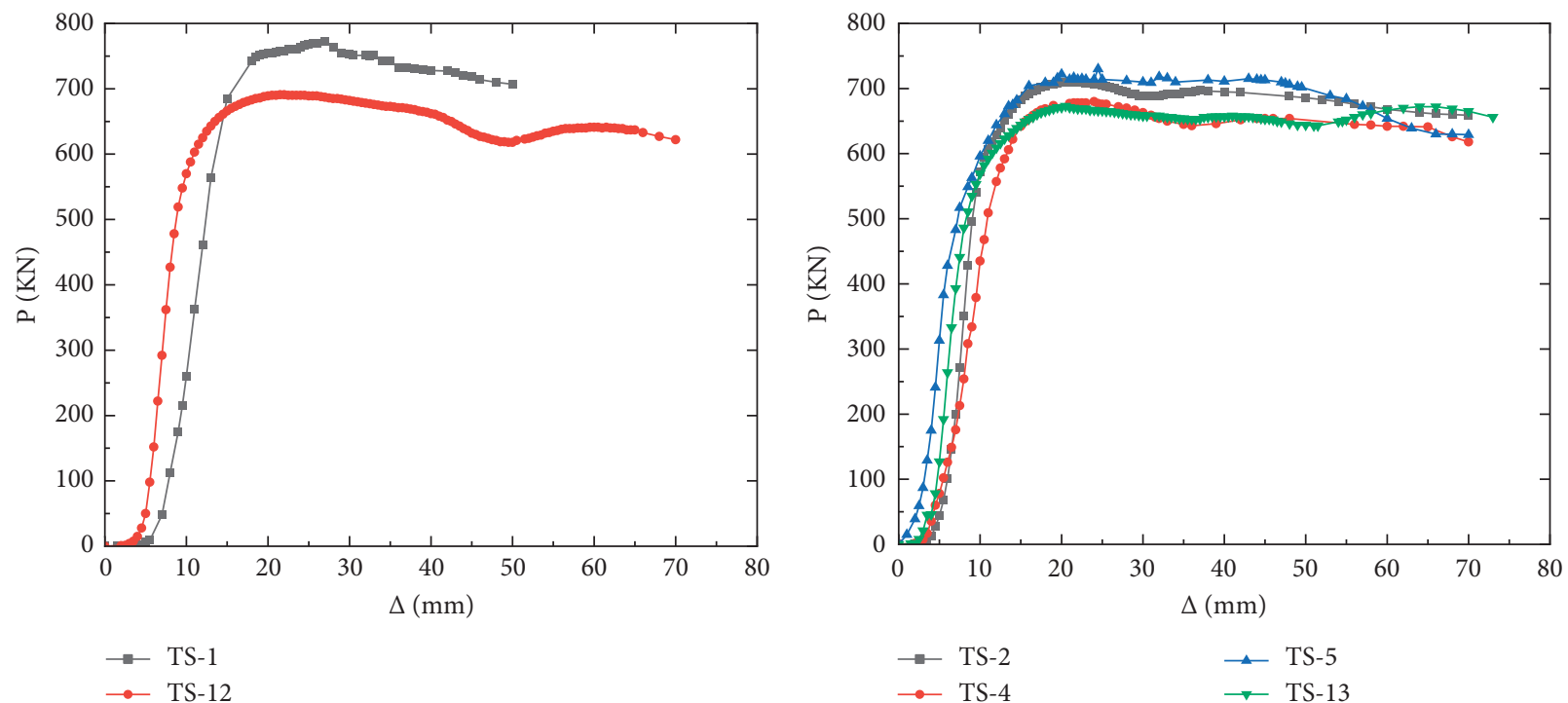

(a)

(b)

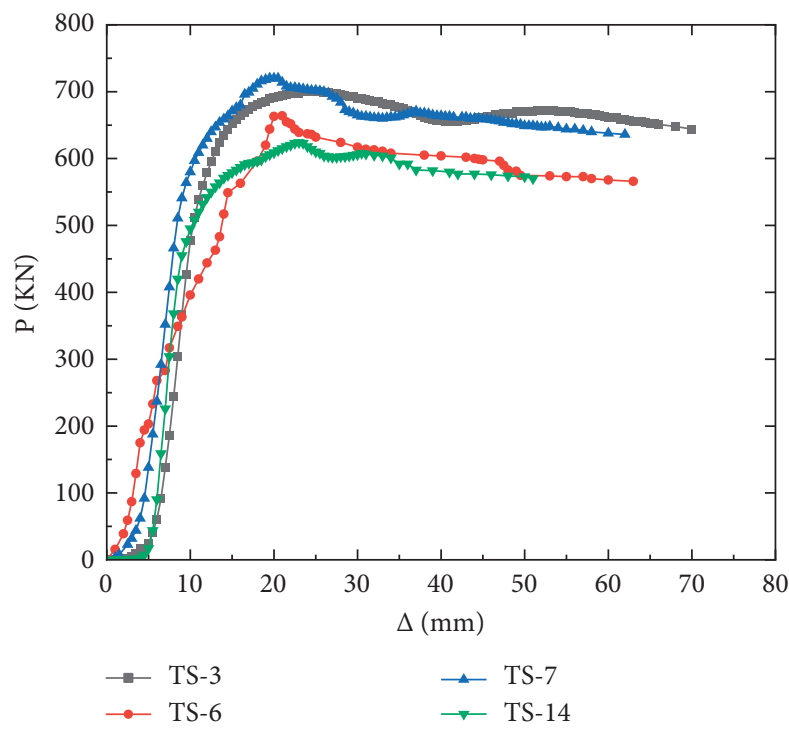

(c)

Figure 6: Load-displacement curve with different SF contents. 


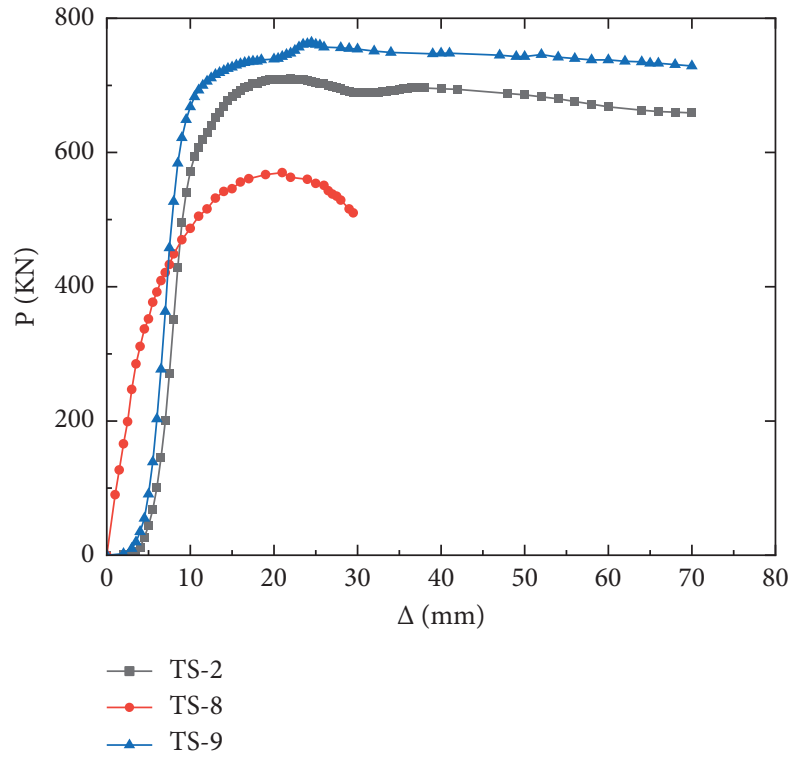

(a)

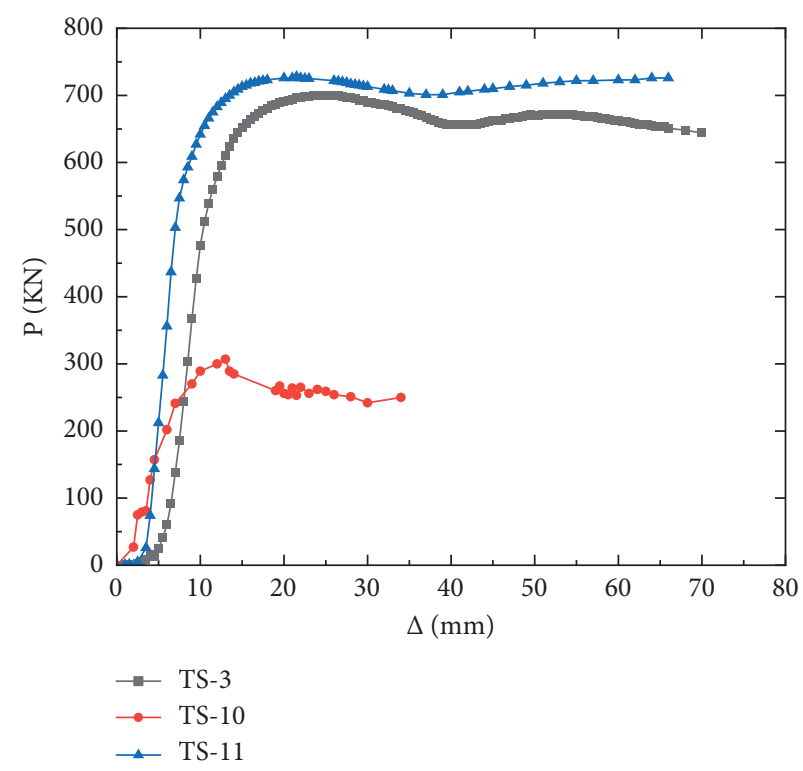

(b)

FIGURE 7: Load-displacement curves with different concrete strengths.

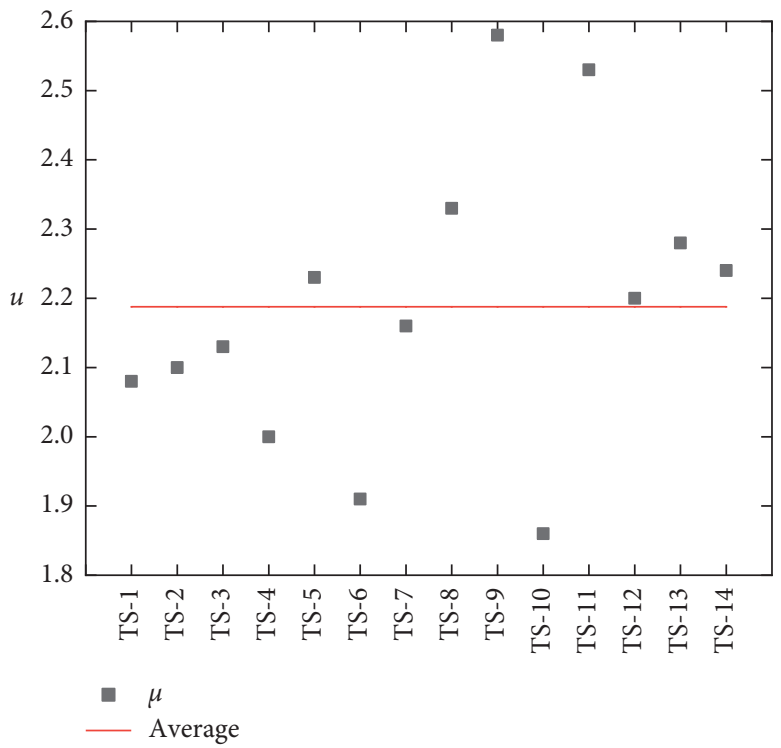

Figure 8: Displacement ductility coefficient.

the range from 2.0 to 2.4 . Furthermore, the ductility of the specimen can be enhanced due to the use of RCA. And, the ductility of the specimen can be decreased due to the addition of a few SF. In addition, the ductility of the specimen increases as increasing SF content or concrete strength.

3.4. Stiffness. To analyze the stiffness change conveniently, the stiffness of specimen 12 is defined as 1 , and the stiffness index (SI) is shown in Figure 5. The concrete strength has a great influence on the secant stiffness. As the concrete strength increases, the stiffness increases. It is worth noting that the maximum stiffness index is that of the TS-5 specimen with $1.2 \%$ SF content. The stiffness of the specimen can be greatly enhanced by adding SF. The use of RCA reduces the stiffness of the specimen, and at the same time, the increase in concrete strength can make up for the stiffness loss caused by RCA.

\section{Conclusions}

Based on the above research results, the following conclusions can be drawn:

The bearing capacity of the columns with SF will be decreased due to using recycled concrete instead of natural concrete. When the steel fiber content or the concrete strength grade is low, the RCA content will 
greatly affect the mechanical performance of the columns.

Incorporating steel fiber into concrete can increase the bearing capacity of the short columns. As the steel fiber content increases, the increasing speed of the bearing capacity for the columns slows down.

The concrete strength has a great effect on the bearing capacity of the columns. It will reduce hugely when the concrete strength increases. The concrete strength has the greatest impact on ductility, whereas the steel fiber content has the least impact on ductility.

The steel fiber and concrete strength has great influences on the stiffness of the short column. The secant stiffness of the specimen increases with the increase of the steel fiber content or concrete strength.

\section{Data Availability}

The data used to support the findings of this study are included within the article.

\section{Conflicts of Interest}

The authors declare that they have no conflicts of interest.

\section{Acknowledgments}

This work was supported by the Chinese National Natural Science Foundation (nos. 51868001 and 52068001), Project of Academic and Technological Leaders of Major Disciplines in Jiangxi Province (no. 20204BCJL2037), and Natural Science Foundation of Jiangxi Province (no. 20202ACBL214017).

\section{References}

[1] S. Sadati and K. H. Khayat, "Restrained shrinkage cracking of recycled aggregate concrete," Materials and Structures, vol. 50, no. 4, pp. 17-27, 2017.

[2] J. Thomas, N. N. Thaickavil, and P. M. Wilson, "Strength and durability of concrete containing recycled concrete aggregates," Journal of Building Engineering, vol. 19, pp. 349-365, 2018.

[3] J. F. Liang, E. Wang, X. Zhou, and Q. L. Le, "Influence of high temperature on mechanical properties of concrete containing recycled fine aggregate," Computers and Concrete, vol. 21, no. 1, pp. 87-94, 2018.

[4] B. M. Vinay Kumar, H. Ananthan, and K. V. Balaji, "Experimental studies on utilization of recycled coarse and fine aggregates in high performance concrete mixes," Alexandria Engineering Journal, vol. 57, no. 3, pp. 1749-1759, 2017.

[5] R. Kurda, J. de Brito, and J. D. Silvestre, "Water absorption and electrical resistivity of concrete with recycled concrete aggregates and fly ash," Cement and Concrete Composites, vol. 160, pp. 37-49, 2018.

[6] A. Wongkvanklom, P. Posi, B. Khotsopha et al., "Structural lightweight concrete containing recycled lightweight concrete aggregate," KSCE Journal of Civil Engineering, vol. 22, no. 8, pp. 3077-3084, 2018.
[7] G. Ren, H. Shang, P. Zhang, and T. Zhao, "Bond behaviour of reinforced recycled concrete after rapid freezing-thawing cycles," Cold Regions Science and Technology, vol. 157, pp. 133-138, 2019.

[8] J. F. Liang, Z. P. Yang, P. H. Yi, and J. B. Wang, "Stress-strain relationship for recycled aggregate concrete after exposure to elevated temperature," Computers and Concrete, vol. 19, no. 6, pp. 609-615, 2017.

[9] J. Z. Xiao, Recycled Concrete Chinese Building Construction Publishing Press, 2008.

[10] T. Li, J. Xiao, C. Zhu, and Z. Zhong, "Experimental study on mechanical behaviors of concrete with large-size recycled coarse aggregate," Construction and Building Materials, vol. 120, no. 1, pp. 321-328, 2016.

[11] M. J. Munir, S. M. S. Kazmi, Y.-F. Wu, I. Patnaikuni, J. Wang, and Q. Wang, "Development of a unified model to predict the axial stress-strain behavior of recycled aggregate concrete confined through spiral reinforcement," Engineering Structures, vol. 218, Article ID 110851, 2020.

[12] M. J. Munir, Y.-F. Wu, S. M. S. Kazmi, I. Patnaikuni, Y. Zhou, and F. Xing, "Stress-strain behavior of spirally confined recycled aggregate concrete: an approach towards sustainable design," Resources, Conservation and Recycling, vol. 146, pp. 127-139, 2019.

[13] J. Xu, Y. Wang, R. Ren, Z. Wu, and T. Ozbakkaloglu, "Performance evaluation of recycled aggregate concrete-filled steel tubes under different loading conditions: database analysis and modelling," Journal of Building Engineering, vol. 30, Article ID 101308, 2020.

[14] Z. Chen, C. Jing, J. Xu, and X. Zhang, "Seismic performance of recycled concrete-filled square steel tube columns," Earthquake Engineering and Engineering Vibration, vol. 16, no. 1, pp. 119-130, 2017.

[15] L. Wang, T. He, Y. Zhou et al., "The influence of fiber type and length on the cracking resistance, durability and pore structure of face slab concrete," Construction and Building Materials, vol. 282, Article ID 122706, 2021.

[16] L. Wang, F. Guo, H. Yang, Y. Wang, and S. Tang, "Comparison of fly ash, PVA fiber, $\mathrm{MgO}$ and shrinkage-reducing admixture on the frost resistance of face slab concrete via pore structural and fractal analysis," Fractals, vol. 29, no. 2, Article ID 2140002, 2021.

[17] J. A. Carneiro, P. R. L. Lima, M. B. Leite, and R. D. Toledo Filho, "Compressive stress-strain behavior of steel fiber reinforced-recycled aggregate concrete," Cement and Concrete Composites, vol. 46, pp. 65-72, 2014.

[18] E. Mohseni, R. Saadati, N. Kordbacheh, Z. S. Parpinchi, and W. Tang, "Engineering and microstructural assessment of fibre-reinforced self-compacting concrete containing recycled coarse aggregate," Journal of Cleaner Production, vol. 168, pp. 605-613, 2017.

[19] D. Gao and L. Zhang, "Flexural performance and evaluation method of steel fiber reinforced recycled coarse aggregate concrete," Construction and Building Materials, vol. 159, pp. 126-136, 2018.

[20] C. Jodilson Amorim, L. Lima, P. Roberto, and B. L. Monica, "Compressive stress-strain behavior of steel fiber reinforcedrecycled aggregate concrete," Cement and Concrete Composites, vol. 46, pp. 65-72, 2014.

[21] L. Wang, M. Jin, F. Guo, Y. Wang, and S. Tang, "Pore structural and fractal analysis of the influence of fly ash and silica fume on the mechanical property and abrasion resistance of concrete," Fractals, vol. 29, no. 2, Article ID 2140003, 2021. 
[22] L. Wang, M. Jin, Y. Wu, Y. Zhou, and S. Tang, "Hydration, shrinkage, pore structure and fractal dimension of silica fume modified low heat Portland cement-based materials," Construction and Building Materials, vol. 272, Article ID 121952, 2021. 